\title{
"Marketing fortification of business through crowdsourcing and social responsibility: focus on South African SMEs"
}

\begin{tabular}{ll} 
AUTHORS & $\begin{array}{l}\text { Eunice Lebogang Sesale } \\
\text { Solly Matshonisa Seeletse }\end{array}$ \\
& $\begin{array}{l}\text { Eunice Lebogang Sesale and Solly Matshonisa Seeletse (2017). Marketing } \\
\text { fortification of business through crowdsourcing and social responsibility: focus on } \\
\text { South African SMEs . Environmental Economics, 8(1), 18-25. } \\
\text { doi:10.21511/ee.08(1).2017.02 }\end{array}$ \\
\hline ARTICLE INFO & http://dx.doi.org/10.21511/ee.08(1).2017.02 \\
\hline DOI & Friday, 07 April 2017 \\
\hline RELEASED ON & $\begin{array}{l}(c) \text { EY } \\
\text { This work is licensed under a Creative Commons Attribution } 4.0 \text { International }\end{array}$ \\
\hline LICENSE & License \\
\hline JOURNAL & "Environmental Economics" \\
\hline ISSN PRINT & $1998-6041$ \\
\hline ISSN ONLINE & $1998-605 X$ \\
\hline PUBLISHER & LLC “Consulting Publishing Company "Business Perspectives" \\
\hline FOUNDER & LLC “Consulting Publishing Company "Business Perspectives"
\end{tabular}

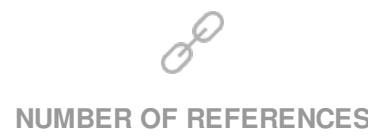

20

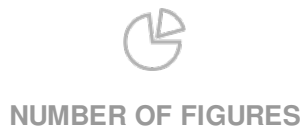

0
NUMBER OF TABLES

0

(C) The author(s) 2023. This publication is an open access article. 
Eunice Lebogang Sesale (South Africa), Solly Matshonisa Seeletse (South Africa)

\title{
Marketing fortification of business through crowdsourcing and social responsibility: focus on South African SMEs
}

\begin{abstract}
This paper investigates networking and related activities for marketing performance of small and medium enterprises (SMEs) for the sustainable development and the preservation of the environment. These SMEs have limited business skills and knowledge, and don`t have any marketing funds. As a clearly growing trend aspect in business, networking approaches were blended to find approaches to help these SMEs to take their market niche. Thirty-seven (37) SMEs were used as a convenience sample to experiment with the concepts. They were investigated on what could optimize marketing results and what could offset marketing benefits. The paper finds out that networking provides effective marketing when is modeled under crowdsourcing. Options for crowdsourcing could also involve local organizations in the marketing networks. SMEs should document their activities for proper accountability and transparency. They should also use incentives to volunteers and crowdsourcing participants by giving them shares and be proactive in their approaches. Further, SME practitioners should require them to learn business skills.
\end{abstract}

Keywords: SMEs, sustainable development, environment, business skills, crowdsourcing, marketing, networking, social responsibility, synergy.

JEL Classification: O12, D63, M14.

\section{Introduction}

Businesses should continuously adjust their commercial strategies to react to the changing conditions of globalization, internationalization, and modernization. Among the strategies for adjusting business is to publicize its trade. Publicizing a business is a major strategy in any business development (Porter, 2008). The formation of marketing networks to implement this strategy is increasing. A network developed through use of many useful people in the form of a crowd is one useful method of the modern marketing. Crowdsourcing implemented in business organization as a business strategy enhances financial performance, sustainable competitive advantage, and ensures business sustainability, among others (Agrawal, Christian \& Avi, 2014). Nevertheless, crowdsourcing has so far received limited attention. In addition, social responsibility was used for this paper to augment crowdsourcing as an experiment to determine the extent to which marketing could be enhanced without financial input.

Wolf (2006) insinuated that many SMEs in South Africa are owned and/or managed by people who lack business skill and knowledge. The items these

(c) Eunice Lebogang Sesale, Solly Matshonisa Seeletse, 2017.

Eunice Lebogang Sesale, Department of Statistics and Operations Research, Sefako Makgatho Health Sciences University, South Africa.

Solly Matshonisa Seeletse, Ph.D., DBA, Professor, Department of Statistics and Operations Research, Sefako Makgatho Health Sciences University, South Africa.

This is an Open Access article, distributed under the terms of the Creative Commons Attribution-NonCommercial 4.0 International license, which permits re-use, distribution, and reproduction, provided the materials aren't used for commercial purposes and the original work is properly cited. owner/managers have in mind when running a business are sales and profits. They have little or no idea as to what makes the sales, such as marketing. They also lack an understanding of financial management and sustainability.

This paper explains crowdsourcing benefits in financially strained SMEs' responsiveness to the marketing demand. It investigates crowdsourcing networks as structures and processes that enhance information sharing around the environment to become beneficial business knowledge. The focus is to explore these networks as relationships by which responsiveness to the market segments becomes strategic and, consequently, sustainable.

\section{Literature review}

1.1. Networking. Networking refers to several people or items of similar interest interacting together to work towards goals of common interest (Peterson, 2003). It is a distinctive blend of strategy, structure and management. Prokopendo (2005) views networking as a technique to extend and create visibility for parties in niches or larger markets. Lavie (2006) interprets networking as a source of business competitive advantage. Network resources are external associates entrenched in the organization's pact system which offer strategic business opportunities. They influence organizational behavior and worth. It is also important to consider the method of relationships for the networks. There may be some forms which are neither optimal nor beneficial. Even strategic networks should be treated with caution. The operational level should always evaluate the worth of a network before applying the network's constituents. 
1.1.1. Networking for business modeling. Networking can become part of the business model. Vashani and Smith (2008) describe networks worth in distribution networking to allow the corporations to implement marketing. A superior vital leverage in business modelling networks is information technology and communication (ITC). ITC connects distribution networks to other corporations, creates business networks to deliver economies of scale while preventing competition impacts (Wysocki, 2013). It also generates a dynamic competitive edge, aids accountability and the creation of international norms, standards, and principles.

1.1.2. Norm-building networks. Transnational normbuilding networks (TNNs) entail a new form of governance operating beyond the nation-state level in promoting global standards that provides a platform for private self-regulation and norm building in areas where traditional state regulation failed or was impossible (Mueckenberger \& Jastram, 2010). Norm-building networks can be linked to a marketing perspective in branding (Werther \& Chandler, 2005). When building trust of the consumer, global branding benchmarks may be used. These could also be described as deliberate relations between and within politics, economy and civil society, which prepares and standardize behavioral rules, norms and conventions in their specific field.

1.1.3. Proactive sustainability networks. According to Nielson and Thomsen (2011), network-oriented initiatives focus on developing and/or maintaining virtuous relations with stakeholders. Research has focused on reactions to environment, while proactive networks have received less attention. Murillo and Lozano (2009) studied university-small and medium size business partnerships implemented to promote sustainability focused networks. Halila (2007) investigated the way SMEs can use networking to promote environmental work. Morsing and Beckman (2006) studied sustainability networking with an array of different organizations (consumer associations, communities, NGOs, trade unions and central and local government). Their concerns centered on the way businesses could become legitimate in the viewpoints of society. These were all proactive, and linked to the corporate branding. They all explain why sustainability corporations develop cooperation and networking among different actors. They manage their role which ranges from dealing with crises emanating from their external environment to improving the effectiveness and reputation of their organizations. Their focus is mainly on corporate communications (Bremer, 2008).
1.1.4. Business networks to implement marketing. Business-to-business (B2B) networks are useful in implementing business promotional programs. Networked businesses provide leadership and support for their communities. They also tend to use local suppliers of goods and services. B2B networking emphasize sustainable development projects (Vashani $\&$ Smith, 2008).

1.2. Marketing. Every business has to be promoted in order to participate in its market. In order to promote a business, the organization involved needs to be marketed. According to Porter and Kramer (2006), marketing refers to using advertisements to help a company to sell its products. Marketing enhances varied business activities, policies and programs in order to optimize profits. Several marketing approaches exist for each business situation, and the one suiting the organization at the time of action is usually used.

1.3. Crowdsourcing. Crowdsourcing is a rational process to get a crowd (large group of people) to work together by locating needed services, ideas, or content by lobbying contributions (Estellés-Arolas \& González-Ladrón-de-Guevara, 2012). Each participant must be willing to participate. Work is often divided between participants who combine their efforts to exceed expectations. Some considerable crowdsourcing paybacks are cost saving, speed, quality, flexibility, scalability, and diversity (Brabham, 2013). In innovation, crowdsourcing enables organizations to learn beyond the employees' capabilities. Both intrinsic and extrinsic drives influence decisions to participate in crowdsourcing. Some reasons for using crowdsourcing is to involve many people to work towards a common goal, such as attention, efficiency, fun, increased quality, innovation, knowledge, money, networking, philanthropy, problem solving, and reputation, among others (Prpić, Taeihagh \& Melton, 2015).

Crowdsourcing can have challenges. Weak participants can lower work quality, displeasure of members, and waste of time (Brabham, 2012). Thus, there should be a robust approach to monitor, evaluate, and correct when deviation against crowdsourcing ideal occurs. Unethical use of crowdsourcing may occur when some members benefit at the expense of others, without giving due acknowledgements to every participant (Busarovs, 2013). Other positive crowdsourcing elements are access to new ideas and solutions, deeper consumer engagement, opportunities for co-creation, optimization of tasks, and reduced costs (Mercuse, 2011), teamwork (Cattani et al., 2013), synergy (Goffee \& Jones, 2013), innovation (Heyne, Boettke 
\& Prychitko, 2010), task optimization (Savulescu \& Persson, 2012) and conflict resolution (Maccoby \& Scudder, 2011; Ishak \& Ballard, 2012), among others.

Consequently, crowdsourcing is a growing trend in the business world, which is particularly evident among multinational corporations (Chandler \& Kapelner, 2013). However, there is little research to explain their worth in SMEs.

1.3.1. Crowdsourcing trend. Due to the desire to expand and be receptive to the markets, organizations link more with other organizations and their stakeholders. Marketing executives involve their employees and associates in brainstorming ideas for expansion. The intensifying expectations and improved connectedness of the modern times make the combination of the business enterprise imperative (Rainey, 2006). The escalation of informational, global economy is branded by an organizational rationality where crowdsourcing plays a key role.

1.3.2. Business crowdsourcing networks. Business crowdsourcing networks (BCNs) are coalitions involving associated organizations that are appropriate to react to the essentials of briskly varying and information opulent business settings (van Heck \& Vervest, 2009). They enable business innovations with the access they afford BCN members to cherished information. They also permit business to establish associations with its operating environment in reaction to the needs and demands of its manifold stakeholders.

\subsubsection{Networks with interest-based alliances.} Wilburn (2009) explained business organization partnering in networks that involve nongovernmental organizations (NGOs), not-for-profit organizations (NFPs), and faith-based organizations (FBOs). Partnering is a cost-effective and affordable technique to assist corporations to avoid the market difficulties. These partnerships offer access to information for new operations. Information provided could concern culture, customs and needs of the people in the areas, among others, where the organization intends to conduct business. Such information enables a networking business to develop scenario analyzis, identify the significances of suggested projects, monitor, evaluate and design interventions to reduce or offset negative impacts of the planned actions. Moreover, alliances enable organizations to understand the socially acceptable behaviors in foreign circumstances.

1.4. The business case for BCNs. BCNs link networks with advantages in acquiring sales and supply chains, and to design and operate production networks (Parkhe, Wasserman \& Ralston, 2006). The SME focuses on what it could perform well, and its associations with other firms enhance high productivity and innovation with limited resources. The BCNs exceed all the phenomena that control the business world, as networks remodel the global business architecture.

1.5. Synergies. Synergy entails involving numerous components to generate a whole that exceeds the sum of the individual quotas (Gillwald, Moyo \& Stork, 2012). It spirals competitiveness, improves strategy and promotes network identity to breed an eccentric tool to compete in the market. Partnerships can become strategic in linking organizational networks and creating synergies (Lattimore \& Von Glinow, 2010). Organizations with dissimilar core competencies can link their existing business networks to resolve a complex business problem. Agility of diverse expertise and marketing networks who understand the local network, coupled with benchmarked experiences, are able to provide larger value for any single business entity of the network. The synergy generated by the networks could increase overall capacity and efficiency of the marketing efforts.

1.6. Social responsibility. Corporate social responsibility entails professional creativities which are not directly connected to corporate economic professional aims, which compel organizations to deviate from solely focusing on making profits to embrace legal, financial, environmental, social responsibility, and so on, in their core professional strategies (Ladzani \& Seeletse, 2010). It is an expert concept that entails operating an enterprise by accounting for the social and environmental impact. It emerged from proper control and accounting, diversity in staffing, compliance invented on the high ethical standards of employees, adoption of operating policies, being responsible for company goods and services, being socially responsible, ensuring employee and customer safety at work, quality and control of company own activities and conduct (Niehm, Swinney \& Miller, 2008). It is an enterprise's deliberate standards and actions to achieve its sustainable development objectives. Ladzani and Seeletse (2012) view social responsibility as a voluntary rule and exercise stretching beyond orthodox regulatory requirements. Social responsibility leaders are enterprises with the potential to influence external stakeholders (such as clients, community, partners, and shareholders, among others) to adopt measures for social development and a broad approach to quality and sustainable development (Nguyen, Skitmore \& Wong, 2009). Enterprises embracing social 
responsibility develop an operational framework to understand its impact and benefits on the environment, consumers, employees, communities, and stakeholders.

Thus, social responsibility envelops management values and principles to guide ethical relationships of business with local communities to enhance sustainable development by preserving available resources for future generations, respecting diversity, and reducing social inequalities. Concepts that fortify social responsibility, therefore, and according to Seeletse and Ladzani (2012), include 'ethics', 'commitment', 'relations', 'transparency', 'sustainable development', 'social accountability' and the 'promotion of the reduction of social inequality'. They stand out in this vision of social responsibility and will be treated in this study.

\section{Purpose of the study}

Marketing is usually an expensive trade referring to a series of diverse business activities, policies and programs not easily explained solely by the need to optimize profits (Kvint, 2016). It often requires investment costs, sometimes huge, some of which are wasted. Thus, marketing becomes difficult for companies that lack funds. This paper discusses some methods to offset this weakness by accomplishing the benefits of marketing efforts while not paying for the expenses. The argument shows that while formal marketing may cost money, use of innovative alternative methods may lead to offsetting the formal marketing drawbacks. Companies can, therefore, avoid marketing endeavors that end up leading to financial losses that cannot be fully accounted for (Hunter, 2000). The specific objectives of this paper are to:

- determine how some interventions in SME marketing enhance marketing successes,

- establish ways to augment SME marketing when there are no funds for marketing, and

- institute feasible methods to optimize marketing results.

\section{Methods}

The methodological trial of the paper was to operationalize networking concepts in enhancing effective marketing of SMEs that lack marketing funds. It was indispensable to identify indicators that could be inspected in documented network reports and corporate websites. The analyzis carried out explored issues of networking as they applied to marketing and the extent to which they were able to substitute the funding of marketing exercises. Thus, thematic content analyzis was conducted to determine those issues.
3.1. SMEs for the study. Thirty-seven (37) SMEs in niche businesses were used in the trial. Twelve (12) of them were based in villages in the NorthWest Province, 16 were from Limpopo Province, and nine (9) were in townships (semi-developed residential areas). These SMEs' trades were distributed into selling indigenous self-breeding vegetables. Other business trades included an epilepsy healer, special clothing sewer, and basic grocery retailer. The third enterprise group consisted of makers of baskets, shoes and blankets; financial services; manufacturing; food services; IT; events management; private schools; allied and medical healthcare organizations; transport services; and management consulting companies. The township enterprises entailed sewing of woven shoes types that were neither sold nor sewn in formal and large retail shops. When they went to Seda, none of these SMEs had marketing funds to promote their businesses.

3.2. Experimentation. As a social responsibility experiment, this study assisted by printing the products of the details sold, and the SME contacts. Thus, it provided the BCN members to distribute the SMEs' products. The rewards of promoting the SMEs' yield consisted of giving some free items from the ones the volunteers advertised, and also giving employees bonuses where excessive profits were realized. The members showcased the items to colleagues at their workplaces, localities/neighbors, and also took orders on behalf of the SMEs. In the case of healing services, the information was shared by exposing the people healed. The volunteers, then, urged their colleagues with painfully ailing relatives to try the services of the healers. The SMEs were encountered at the Small Enterprise Development Agency (Seda) seeking support. They were, then, voluntarily sampled through purposive sampling of the general convenient sampling method.

3.3. Data collection. Data collection entailed gathering empirical data related to the way the 37 SMEs promoted/marketed their businesses. The SMEs were requested to indicate their approach in crowdsourcing networking. The outsourcing aspect was new to most of the SME owners, and it did not seem to attract them. Primary data were collected using surveys by the researchers. The principal focus was to describe the ways these SMEs self-reported their engagement in $\mathrm{BCN}$. The most important of these sources was selfreported information regarding the corporation's approach to $\mathrm{BCN}$. 
3.4. Data analyzis. This stage involved evaluating collected self-reported data on the details of BCN actions in promoting the SMEs. Data analyzis was performed using thematic content analyzis of reports of the SMEs in the past three years.

\section{Results}

4.1. Networking. All the involved members in the networks formed were satisfied buyers of the SMEs' yields. They wanted more consumers to also benefit from the use of these items, and to improve the lacking exposure of the items. The products of the SMEs became more visible at a small scale of their marketing. The associate SME members shared the same interest of selling the yield. The efforts of each BCN member boosted the competitiveness of the SMEs, thus, prompting a belief that the competitive advantages of these SMEs had been heightened. The change in organizational behavior included finding market segments of importance, and an increase in new stakeholders. These were also role players, particularly in the marketing endeavors of the SMEs. Further, the worth of each of the SMEs was enhanced by increased profits.

4.1.1. Networking for business modeling. None of the networks leveraged using ICT, but they all knew the possibilities of ICT usage. Though the SMEs networked, networking was not necessarily part of their business model. It was basically seen as conditional on existing results. Also, if the order of products were inadequately few, delays in productions would be made or halted indefinitely. However, networking surely aided accountability and the creation of international norms, standards, and principles.

4.1.2. Norm-building networks. The SMEs were limited in their networking. They could neither reach TNNs nor any norm-building networks form. They operated as niches, and their marketing networks were fragile. They did not operate beyond their localities even when using their networks. The SMEs attempted vastly to build consumer trust, but they could not use global branding benchmarks. Only the networks could move out of the localities with the items ordered. As a result, norm-building networks could not be associated to a marketing perspective in branding. These could also be described as deliberate relations between and within politics, economy and civil society which prepares and standardizes behavioral rules, norms and conventions in their specific field.

4.1.3. Proactive sustainability networks (PSNs). Some networking was initiative, which developed and maintained worthy relations with some SME clients. These initiatives lead to proactive marketing efforts from the SMEs. Since these SMEs operated intermittently, measuring their sustainability proved to be difficult. The PSNs were fundamentally limited to individual SMEs. They confidently improved these SMEs' corporate communications, and, thus, provided a platform for sustainability.

4.1.4. Business networks to market. B2B networks did not feature in implementing business promotional programs of these SMEs. They, therefore, could neither provide business leadership nor support communities. On the positive side, they still used local suppliers of goods and services for stock, probably because they have no other options. B2B networking emphasizes sustainable development projects.

4.2. Marketing. The networks created promoted the SMEs, enabling them to participate in their limited markets. The SMEs lacked resources. Their marketing could not enhance wide-ranging business activities, policies and programs. They also could not optimize profits even though the profits had increased. Also, their marketing approaches were limited to their pockets, and they lacked the latitude to follow marketing options which suited their SMEs.

4.3. Crowdsourcing. Crowdsourcing benefitted the SMEs. The buyers of the products were employees in different workplaces volunteering to spread the word about the admirable items sold by these SMEs. Also, the crowds operated at a distance, by telephoning one another. Some considerable crowdsourcing paybacks achieved included cost saving, speed, quality, flexibility, scalability, and diversity. The crowdsourcing did not reach levels of NGOs, NFPs and FBOs due to their limited nature.

4.4. The business case for BCNs. The volunteers formed the BCNs. They managed to link the advantages of more sales of their items/productivity. The SMEs also demonstrated more competitiveness and increased sales. However, productivity depended on adequate orders of the items made. This was not always possible. The ability of an organization to focus on the aspects it performs well, and its associations with other firms, enhance high productivity and innovation with limited resources. Therefore, BCNs can help organizations to meet the challenges of change. The mounting intricacy of products, services and their design, production and delivery also stimulate the usage of BCNs. The BCNs exceeded all the phenomena that rule business.

4.5. Synergies. Use of the networks coincided with the realization of synergies, as much more sales were realized after the BCNs assisted in marketing the SMEs' items. 
4.6. Social responsibility. The initial intent was to assist the SMEs to market their yield in what was originally intended to be a social responsibility initiative. However, the volunteers who assisted the SMEs with marketing did not refuse compensation after the SMEs made profits. In the real meaning of social responsibility, the whole exercise ended up becoming commission-based. These evolved away from the core attributes of social responsibility, but still assisted the SMEs to make profits. The SMEs did not grow in size, but some of the rural enterprises continued to generate more revenue. They were sustainable, while $16(43 \%)$ others continued their intermittent patterns of doing business.

4.7. Missing aspects. While $18(49 \%)$ of the rural SMEs managed to produce and sell more items, none of them had managed to diversify their products. Also, the SMEs did not record transactions made from the BCNs. These showed that no taxes were paid from the increased revenue, thus indicating a lack of ethical conduct. Commitment was clear only from the rural ones that sold more, but was not measurable in the other two. The BCN relations were continuous only in the rural ones, but not in the others. Lack of recording led to lack of transparency in the SMEs' activities. The issue of sustainable development was more likely in the rural ones that had improved, but was not materializing. It was clearly non-existent in the others. They all lacked in social accountability, mainly by not disclosing using written records. They also all played no role in promoting the reduction of social inequality.

\section{Discussion}

5.1. Networking. Networking occurred, but a notable proportion of the SMEs did not aggressively embrace their advantage in marketing and productivity. They were reactive by waiting for the yield, and did not formally discuss ways to increase or augment their marketing. They also waited for revenue before their next action. Even then, 21 (57\%) of the SMEs still did not leverage on the BCNs' fortifications. Only four (33\%) of the 12 rural ones embraced some efforts of the BCNs. These SMEs did not use ICTs, despite the indication that ICTs provide some business advantage. The norm-building networks were also not used in the BCNs. These benefits were, then, excluded in the SMEs' business models. Sustainability potentials of the SMEs were also not boosted, mainly due to the reactive approach instead of the proactive approach which is possible through planning. There were also no B2B leverages involved in these SMEs. Despite the limited use of the methods, networking certainly aided some accountability and the creation of international norms, standards, and principles.

5.2. Marketing. The networks assisted in promoting the SMEs. However, this occurred only on a part-time basis, as the owners were on their full time jobs. Despite this weakness, the networks still enabled the SMEs to sell their products even more. However, these marketing initiatives did not enhance wide-ranging business activities, policies and programs. They could increase profits, but could not optimize them. Due to lacking funds, the SMEs could not follow marketing options of their choices.

5.3. Crowdsourcing. The main advantage experienced by the SMEs was crowdsourcing, which enabled items to come out of the SMEs' 'hideouts' to the consumers. The paybacks were cost saving, speed, quality, flexibility, scalability, and diversity, but crowdsourcing could not lead to networks with NGOs, NFPs and FBOs.

5.4. The business case for BCNs. The BCNs undoubtedly led to more sales, and, hence, more revenue. These also indicated more competitiveness of the SMEs, but productivity levels were not showing piercing growths in some of the SMEs. New innovations were not showing to have been emerging.

5.5. Synergies. The synergies between the SMEs and the BCNs were visible. However, the SMEs were not necessarily conscious about the concept and its use in business. Also, there was little learning as over half (51\%) of the SMEs evidently raised their business games afterwards.

5.6. Social responsibility. The initial promise when the volunteers offered to assist the SMEs to market the SMEs'products did not give a price, and they gave the impression that they would not charge for their services. If this had ben adhered to, this assistance to market for the SMEs would have been a social responsibility implementation. However, the volunteers accepted compensation after the SMEs made profits and offered to reward them. In the end, the exercise became commission-based. The exercise also did not help the SMEs to grow. Nevertheless, seven $(58 \%)$ of rural SMEs, which is $19 \%$ of all the SMEs in the study, made more business, became sustainable, while the others did not show to improve.

5.7. Missing aspects. Only four (33\%) of rural SMEs produced and sold more items. None of the SMEs increased their business offerings. Also, no SME recorded transactions of their businesses. They paid no taxes from their revenue. They showed no ethical conduct. More commitment was shown in three (25\%) 
rural ones that sold more. However, this was not the case in the other nine (75\%). NBC approaches were continuous in the former three SMEs, but more intermittently in the others. Transactions were not recorded, and transparency lacked in the SMEs' activities. Sustainable growth was more likely in the former three SMEs, but did not show to materialize at the time of the study. This development was less unlikely in the other nine SMEs. All these SMEs lacked social accountability, and none played any role to reduce social inequality.

\section{Conclusions}

Networking. Networks were formed around the SMEs by various supporting parties, and they marketed the SMEs. These networks did not involve ICTs, and also did not model the SME business around the networks, businesses continued their small scale dealings, BCNs boosted the SMEs' competitiveness, and improved organizational behaviors. These were also role players, particularly in the marketing endeavors of the companies. Further, the wealth of the SMEs was enriched by increased profits. Accountability still lacked in virtually all SMEs. The SMEs also did not reach norm-building networks as they chose to remain small niche business. Their business approaches were reactive, not proactive.

Marketing. The networks that emerged promoted and marketed the SMEs. This ensued despite the SMEs having limited resources. Their marketing was suboptimal, could increase profits, but did not optimize profitability. Limited funds restricted the SMEs to few marketing options. They did not apply B2B marketing.

Crowdsourcing. Crowdsourcing benefitted the SMEs with paybacks such as cost savings, speed, quality, flexibility, scalability, and diversity. The crowdsourcing did not reach levels of NGOs, NFPs and FBOs, and this was apparently due to their limited nature.

The business case for BCNs. The BCNs demonstrated to improve the marketing of the SMEs. However, the marketing efforts were clearly suboptimal. Adequate evidence was clear, though, that revenue increased from heightened sales, and competitiveness.

Synergies. The networks ensured that the SMEs' synergies were achieved, albeit at suboptimal levels. The aspects investigated indicate to be relevant when there is a need to optimize marketing in South African SME management.

Social responsibility. Social responsibility lacked in the SME marketing engagements, since the volunteers who had planned to support with marketing ended because commission-based as the volunteers were rewarded.

Missing aspects. The SMEs did not diversify their markets, did not record transactions, paid no taxes, and, therefore, lacked ethical conduct. Commitment increased in only some of the SMEs, BCN relations did not exist in some SMEs, transparency in the SMEs operations was lacking, sustainable development was less likely in some of the SMEs, the SMEs were generally social unaccountable, and they did not promote the reduction of social inequality.

\section{Recommendations}

The initially social responsibility volunteers who turned beneficiaries indicated that they could become long-term marketing and sales participants through incentives, as they accepted rewards. Few or no business lessons seemed to have been learnt by the SMEs. However, the creation of BCNs under crowdsourcing for marketing is still encouraged. Once these have been established, it is recommended that the SMEs should:

- transform the BCNs to become business partners by offering shares to the volunteers;

- extend crowdsourcing partners to include local social structures and the NGOs, NFPs and FBOs;

- record business transactions in order to enforce transparency and accountability;

- learn the business aspects in order to grow and nurture the SMEs.

\section{References}

1. Agrawal, A., Christian, C. \& Avi, G. (2014). Some simple economics of crowdfunding, National Bureau of Economic Research, pp. 63-97.

2. Brabham, D.C. (2012). Motivations for participation in a crowdsourcing application to improve public engagement in transit planning, Journal of Applied Communication Research, 40, pp. 307-328.

3. Brabham, D.C. (2013). Crowdsourcing, London: The MIT Press.

4. Bremer, J.A. (2008). How global is the global compact? Business Ethics: A European Review, 17 (3), pp. 227-244.

5. Busarovs, A. (2013). Ethical aspects of crowdsourcing, or is it a modern form of exploitation, International Journal of Economics \& Business Administration, 1 (1), pp. 3-14.

6. Cattani, G., Ferriani, S., Marianiz, M.M. \& Mengoli, S. (2013). Tackling the 'Galácticos' effect: Team familiarity and the performance of star-studded projects, Industrial and Corporate Change, 22 (6), pp. 1629-1662.

7. Chandler, D. \& Kapelner, A. (2013). Breaking monotony with meaning: Motivation in crowdsourcing markets, Journal of Economic Behavior \& Organization, 90, pp. 123-133. 
8. Estellés-Arolas, E. \& González-Ladrón-de-Guevara, F. (2012). Towards an integrated crowdsourcing definition, Journal of Information Science, 38 (2), pp. 189-200.

9. Gillwald, A., Moyo, M. \& Stork, C. (2012). Understanding what is happening in ICT in South Africa. Cape Town: Research ICT Africa.

10. Goffee, R. \& Jones, G. (2013). Creating the best workplace on the earth, Harvard Business Review, pp. 99-106.

11. Halila, F. (2007). Networks as a means of supporting the adoption of organizational innovations in SMEs: the case of Environmental Management Systems (EMSs) based on ISO 14001, Corporate Social Responsibility \& Environmental Management, 14 (3), pp. 167-181.

12. Heyne, P., Boettke, P.J. \& Prychitko, D.L. (2010). The economic way of thinking, $12^{\text {th }}$ edition. Prentice Hall.

13. Hunter, B.R. (2000). Data loss prevention best practices: managing sensitive data in the enterprise. New York: Ironport Systems.

14. Ishak, A.W. \& Ballard, D.I. (2012). Time to re-group: A typology and nested phase model for action teams, Small Group Research, 43 (1), pp. 3-29.

15. Kvint, V. (2016). Strategy for the global market: Theory and practical applications, London: Routledge.

16. Ladzani, W. \& Seeletse, S. (2010). The status of business social responsibility among SMMEs in the built environment of Gauteng Province, South Africa, ACTA Structilia, 17 (2), pp. 29-52.

17. Ladzani, M.W. \& Seeletse, S.M. (2012). Business social responsibility: How are SMEs doing in Gauteng, South Africa? Social Responsibility Journal, 8(1), pp. 87-99.

18. Lattimore, M.S. \& Von Glinow, M.A.Y. (2010). Organizational behavior: Emerging knowledge and practice for the real world, $5^{\text {th }}$ edition. Boston: McGraw-Hill Irwin.

19. Lavie, D. (2006). The competitive advantage of interconnected firms: An extension of the resource-based view, Academy of Management Review, 31 (3), pp. 638-658.

20. Maccoby, M. \& Scudder, T. (2011). Leading in the heat of conflict, Training and Development, 65, pp. 46-51.

21. Mercuse, P. (2011). Cities for people, not for profit, New York: Routledge.

22. Morsing, M. \& Beckmann, S.C. (2006). Strategic CSR Communication, Copenhagen, Djøf Publishing.

23. Mueckenberger, U. \& Jastram, S. (2010). Transnational norm-building networks and the legitimacy of corporate social responsibility standards, Journal of Business Ethics, 97 (2), pp. 223-239.

24. Murillo, D. \& Lozano, J.M. (2009). Pushing forward SME CSR through a network: an account from the Catalan model, Business Ethics: A European Review, 18(1), pp. 7-20.

25. Nguyen, N.H., Skitmore, M. \& Wong, J.K.W. (2009). Stakeholder impact analyzis of infrastructure project management in developing countries: A study of perceptions of project managers in state-owned engineering firms in Vietnam, Construction Management and Economics, 136 (5), pp. 1129-1140.

26. Niehm, L.S., Swinney, J. \& Miller, N.J. (2008). Community social responsibility andits consequences for family business performance, Journal of Small Business Management, 46 (3), pp. 331-350.

27. Nielsen, A.E. \& Thomsen, C. (2011). Sustainable development: the role of network communication, Corporate Social Responsibility \& Environmental Management, 18 (1), pp. 1-10.

28. Parkhe, A., Wasserman, S. \& Ralston. (2006). New frontiers in network theory development, Academy of Management Review, 31 (3), pp. 560-568.

29. Peterson, L.L. \& Davie, B.S. (2003). Computer networks: A systems approach, New York: Morgan Kaufmann.

30. Porter, M.E. (2008). On competition, updated and expanded edition, HBS Press Book.

31. Porter, M.E. \& Kramer, M.R. (2006). Strategy and society: The link between competitive advantage and corporate social responsibility, Harvard Business Review, 84 (12), pp. 78-92.

32. Prokopendo, J. (2005). Globalization, alliances and networking: A strategy for competitiveness and productivity Employment Sector, Enterprise and Management Development Working Paper.

33. Prpić, J., Taeihagh, A. \& Melton, J. (2015).The fundamentals of policy crowdsourcing, Policy \& Internet, 7 (3), pp. 340-361, September.

34. Rainey, D.L. (2006). Sustainable business development: inventing the future through strategy, innovation, and leadership, Cambridge University Press.

35. Savulescu, J. \& Persson, I. (2012). Unfit for the future: The urgent need for moral enhancement, Oxford: Oxford University Press.

36. Seeletse, S.M. \& Ladzani, M.W. (2012). Social responsibility in the rural businesses of the North-West Province of South Africa: coerced or business-driven? African Journal of Business Management, 6 (46), pp. 11457-11471.

37. Vashani, S. \& Smith, N.C. (2008). Socially responsible distribution: Distribution strategies for reaching the bottom of the pyramid, California Management Review, 50 (2), pp. 52-54.

38. van Heck, E. \& Vervest, P. (2009). Smart business networks: Concepts and empirical evidence, Decision Support Systems, 47 (4), pp. 275-276.

39. Werther, W.B.J. \& Chandler, D.B. (2011). Strategic corporate social responsibility: Stakeholders in a global environment, Thousand Oaks, California, Sage Publications, Inc.

40. Wilburn, K. (2009). A model for partnering with not-for-profits to develop socially responsible businesses in a global environment, Journal of Business Ethics, 84, pp. 111-120.

41. Wolf, S. (2006). Encouraging innovation and productivity growth in Africa to create decent jobs. Paper presented at The DPRU/TIPS Coherence, $18^{\text {th }}$ to $20^{\text {th }}$ October, Johannesburg, South Africa.

50. Wysocki, R.K. (2013). Effective project management: Traditional, adaptive, extreme, $7^{\text {th }}$ edition. New York: Wiley. 